\title{
A 3-year follow-up study of atropine treatment for progressive myopia in Europeans
}

\author{
Jan Roelof Polling ${ }^{1,2,3} \cdot$ Emily Tan $^{1} \cdot$ Sjoerd Driessen ${ }^{3} \cdot$ Sjoukje E. Loudon $^{1} \cdot$ Hoi-Lam Wong ${ }^{1} \cdot$ \\ Astrid van der Schans ${ }^{1} \cdot$ J. Willem L. Tideman ${ }^{1,3} \cdot$ Caroline C. W. Klaver $\mathbb{D}^{1,3,4,5}$
}

Received: 2 July 2019 / Revised: 4 May 2020 / Accepted: 29 July 2020 / Published online: 21 September 2020

(c) The Author(s) 2020. This article is published with open access

\section{Learning Objectives}

Upon completion of this activity, participants will be able to:

1. Distinguish the most salient pathological feature of high myopia.

2. Evaluate the long-term tolerability of atropine eye drops for myopia.

3. Analyze the long-term efficacy of atropine eye drops for myopia.

4. Assess variables that might alter the efficacy of atropine eye drops for myopia.

\section{Continuing Medical Education}

In support of improving patient care, this activity has been planned and implemented by Medscape, LLC and Springer Nature. Medscape, LLC is jointly accredited by the Accreditation Council for Continuing Medical Education (ACCME), the Accreditation Council for Pharmacy Education (ACPE), and the American Nurses Credentialing Center (ANCC), to provide continuing education for the healthcare team.

Medscape, LLC designates this Journal-based CME activity for a maximum of 1.00 AMA PRA Category 1 Credit(s). Physicians should claim only the credit commensurate with the extent of their participation in the activity.

All other clinicians completing this activity will be issued a certificate of participation. To participate in this journal CME activity: (1) review the learning objectives and author disclosures; (2) study the education content; (3) take the post-test with a 75\% minimum passing score and complete the evaluation at www.medscape.org/journal/eye; (4) view/print certificate.

\section{Credit hours}

1.0

Release date:

Expiration date: 21 September 2021

Post-test link: https://medscape.org/eye/posttest 934752

Caroline C. W. Klaver

c.c.w.klaver@erasmusmc.nl

1 Department Ophthalmology, Erasmus Medical Center, Rotterdam, The Netherlands

2 Department Optometry \& Orthoptics, Faculty of Health, University of Applied Sciences, Utrecht, The Netherlands

3 Department Epidemiology, Erasmus Medical Center, Rotterdam, The Netherlands

4 Department of Ophthalmology, Radboud University Medical Centre, Nijmegen, Gelderland, The Netherlands

5 Institute of Molecular and Clinical Ophthalmology, Basel, Switzerland

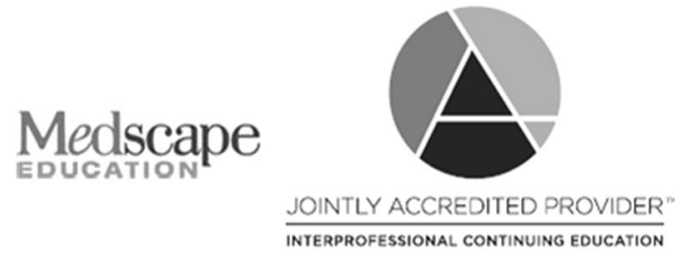

\section{Authors/Editors disclosure information}

Sobha Sivaprasad, MD, has disclosed the following relevant financial relationships: served as an advisor or consultant for: Allergan, Inc.; Apellis; Bayer AG; Boehringer Ingelheim Pharmaceuticals, Inc.; Heidelberg Pharma GmbH; Novartis; Oculis; Optos; Oxurion; Roche. Served as a speaker or a member of a speakers bureau for: Allergan, Inc.; Bayer AG; Novartis Pharmaceuticals Corporation; Optos. Received grants for clinical research from: Allergan, Inc.; Bayer AG; Boehringer Ingelheim Pharmaceuticals, Inc.; Novartis Pharmaceuticals Corporation; Optos. Jan Roelof Polling, MD, has disclosed the following relevant 
financial relationships: served as an advisor or consultant for: Théa Laboratories; Nevakar, Inc. Emily Tan, MD, has disclosed no relevant financial relationships. Sjoerd Driessen, MD, has disclosed no relevant financial relationships. Sjoukje E. Loudon, MD, has disclosed no relevant financial relationships. Hoi-Lam Wong, MD, has disclosed no relevant financial relationships. Astrid van der Schans, MD, PhD, has disclosed no relevant financial relationships. J. Willem Tideman, MD, has disclosed no relevant financial relationships. Caroline C. W. Klaver, MD, $\mathrm{PhD}$, has disclosed the following relevant financial relationships: served as an advisor or consultant for: Bayer AG; Nevakar, Inc.; Novartis Pharmaceuticals Corporation; Théa Laboratories.

\section{Journal CME author disclosure information}

Charles P. Vega, MD, has disclosed the following relevant financial relationships: served as an advisor or consultant for: GlaxoSmithKline; Johnson \& Johnson Pharmaceutical Research \& Development, L.L.C. Served as a speaker or a member of a speakers bureau for: Genentech, Inc.; GlaxoSmithKline.

\section{Abstract}

Background Atropine is the most powerful treatment for progressive myopia in childhood. This study explores the 3-year effectiveness of atropine in a clinical setting.

Methods In this prospective clinical effectiveness study, children with progressive myopia $\geq 1 \mathrm{D} /$ year or myopia $\leq-2.5 \mathrm{D}$ were prescribed atropine $0.5 \%$. Examination, including cycloplegic refraction and axial length (AL), was performed at baseline, and follow-up. Outcome measures were spherical equivalent (SER) and AL; annual progression of SER on treatment was compared with that prior to treatment. Adjustments to the dose were made after 1 year in case of low (AL $\geq$ $0.3 \mathrm{~mm} /$ year) or high response ( $\mathrm{AL}<0.1 \mathrm{~mm} /$ year) of $\mathrm{AL}$.

Results A total of 124 patients were enrolled in the study (median age: 9.5, range: 5-16 years). At baseline, median SER was $-5.03 \mathrm{D}$ (interquartile range (IQR): 3.08); median $\mathrm{AL}$ was $25.14 \mathrm{~mm}$ (IQR: 1.30 ). $N=89$ (71.8\%) children were persistent to therapy throughout the 3-year follow-up. Median annual progression of SER for these children was -0.25D (IQR: 0.44); of AL $0.11 \mathrm{~mm}$ (IQR: 0.18). Of these, $N=32(36.0 \%)$ had insufficient response and were assigned to atropine $1 \% ; N=26$ (29.2\%) showed good response and underwent tapering in dose. Rebound of AL progression was not observed. Of the children who ceased therapy, $N=9$ were lost to follow-up; $N=9$ developed an allergic reaction; and $N=17(19.1 \%)$ stopped due to adverse events.

Conclusion In children with or at risk of developing high myopia, a starting dose of atropine $0.5 \%$ was associated with decreased progression in European children during a 3-year treatment regimen. Our study supports high-dose atropine as a treatment option for children at risk of developing high myopia in adulthood.

\section{Introduction}

The prevalence of myopia is increasing all over the world, and has reached the highest frequencies in young adults in South Korea (96.5\%), but has also increased significantly in Europe $(49.2 \%)[1,2]$. The trait is determined by several optical components, of which increased axial length (AL) is the most important [3]. High myopia, i.e. refractive errors $-6 \mathrm{D}$ or more, has increased from 4.2 to $21.6 \%$ in EastAsians and from 1.4 to $5.3 \%$ in Europeans $[2,4]$. Countries which presently have a low prevalence will follow these trends, as myopia prevalence is driven by lifestyle changes such as less time outdoors and increased near work activities [5]. Myopia carries a significant risk of retinal detachment, glaucoma, and myopic macular degeneration, which is most prominent for severe refractive errors [6]. Of those with high myopia, one in three develops bilateral severe visual impairment or blindness with age [7]. This highlights the need for myopia control strategies in children with progressive myopia, in particular progression to high myopia $[5,8,9]$.

During the last 10 years, many intervention studies for myopia progression have emerged [10-12]. Although lifestyle adjustments and optical solutions can be effective, pharmacological interventions targeting muscarinic receptors have shown the highest efficacy on reduction of eye growth [13, 14]. Atropine is a nonselective muscarinic receptor antagonist which has been tested for progressive myopia in several dosages [10]. High dosages, 0.5 and $1 \%$, are the most effective in reducing eye growth, but have drawbacks as pupil dilatation, loss of accommodation, and potential rebound of spherical equivalent of refraction (SER) after stopping [15]. The lowest dose of atropine, $0.01 \%$, has become popular because it has minimal side effects and virtually no rebound after stopping, but reduction on AL progression is also minimal [16-18].

In an earlier study, we reported 1 year results of intervention with atropine $0.5 \%$ for progressive myopia in a 
clinical setting in Europe. In children with already severe myopic refractive errors (mean SER, -6.6D) and progression of myopia 1D/year or more, we showed that atropine $0.5 \%$ reduced myopia progression to $0.1 \mathrm{D} /$ year. Despite the side effects, persistence to therapy was $78 \%$ [19]. We extended this study, and now report 3-year follow-up after the starting dose of atropine $0.5 \%$. We addressed the photophobia and accommodation problems by prescribing photochromic multifocal spectacles.

\section{Materials and methods}

\section{Study design and population}

The design was a prospective clinic-based effectiveness study. The setting was a single center study in the Erasmus Medical Center in Rotterdam, the Netherlands, which included the Sophia Children's hospital. Erasmus Medical Center has been a referral center for myopia control since 2010. Two examiners (JRP and AS) obtained cycloplegic refractive error and $\mathrm{AL}$ in the children throughout the study. Inclusion criteria have been described previously [19]. In short, consecutive children 5-16 years presenting with SER progression rate of at least $1 \mathrm{D} /$ year, or an SER of at least $-2.5 \mathrm{D}$ in children 10 years and younger, or SER -5.0D in children aged 11 years or older were eligible. Exclusion criteria included those with pediatric pathology (e.g., amblyopia, strabismus, or systemic disorders) and low vision due to retinal dystrophies. The current report included children who presented at our clinic between March 2011 and January 2015. Children and parents received a patient information leaflet followed by oral consultation, and participants provided written informed parental consent (parents or legal guardians and children when age 12 + years; only parents and legal guardians when age $<12$ years). All patients were scheduled for follow-up visits every 6 months from baseline onwards. The occurrence of serious adverse events was noted in the medical chart, and affected patients were referred to a specialist. The study adhered to the tenets of the Declaration of Helsinki, and was approved by the Institutional Review Board of the Erasmus Medical Center.

\section{Intervention}

The intervention at baseline was atropine eye drops $0.5 \%$; both eyes were treated before bedtime. After at least 1 year of atropine $0.5 \%$, adjustments to the dose were made in case of insufficient response or stability of SER and AL. Insufficient response was considered present when myopia progressed $\geq$ $-1 \mathrm{D} / \mathrm{year}$, and $\mathrm{AL}$ increased $\geq 0.3 \mathrm{~mm} / \mathrm{yr}$. Moderate response was defined as SER $\geq-0.5$ to $-1 \mathrm{D} /$ year and $\mathrm{AL} \geq 0.2-0.3$ $\mathrm{mm} /$ year; and good response as SER $<-0.5 \mathrm{D} /$ year and $\mathrm{AL}<$ $0.2 \mathrm{~mm} /$ year [15]. In children with good response, atropine concentration was tapered to $0.25 \%$, and further to 0.1 and $0.01 \%$ every 6 months when myopia progression remained stable. Increase of atropine concentration was indicated if the progression was moderate to insufficient. All dosages were distributed in multi dose bottles preserved with benzalkonium chloride, sodium edetate, boric acid, and purified water (FNA Dutch pharmacists).

\section{Eye examination}

A standardized ophthalmological examination was performed at baseline, and at $6,18,24,30$, and 36 months. Baseline and follow-up measurements included a cycloplegic refractive error measurement with two drops of cyclopentolate $1 \%$ with $5 \mathrm{~min}$ interval and a minimum waiting time of $45 \mathrm{~min}$ after the first drop. In very dark irises with pupil diameter $<6 \mathrm{~mm}$ an additional drop of cyclopentolate was adjusted. In case of atropine 0.5 and $1 \%$ interventions, cycloplegia was considered already present. Refractive error was measured by using a Topcon auto refractor (KR8900). At least three measurements per eye were averaged to the mean refractive error per eye. SER was calculated as the average sphere $+1 / 2$ cylinder of both eyes. AL was measured with the IOL Master (Carl Zeiss MEDITEC IOLMaster 500, Jena, Germany) and for AL five measurements per eye were averaged to a mean AL. The average AL of both eyes was used for the analysis. Bestcorrected Snellen visual acuity was performed at $6 \mathrm{~m}$ distance with a decimal equivalent. The LogMAR based Dutch Radner chart was used to assess binocular reading visual acuity at 25 or $40 \mathrm{~cm}$. To assess compliance with atropine eye drops, dynamic retinoscopy was performed according standard protocol to detect presence of accommodation paralysis and the Richmond Products Clear Pupilometer was used to measure pupil size (Albuquerque, NM, USA).

\section{Statistical analysis}

Primary outcome was the annual progression rate of SER and $\mathrm{AL}$ for years $1-3$. The pretreatment progression rate of SER was calculated using cycloplegic refractive error measurements obtained from medical records. Both SER and $\mathrm{AL}$ showed a skewed distribution; therefore medians were calculated as well as the interquartile range (IQR). Differences in outcomes between the various dosing regimens and between prolongation and cessation of therapy were assessed with Mann-Whitney $U$ nonparametric test for continuous outcome measures, and with Fisher's exact test for categorical outcome measures. Differences in progression rates in SER and AL were obtained with Wilcoxon signed-rank test. Correlation between annual progression of SER and AL was calculated with Pearson's regression analysis. Throughout the study, $p<0.05$ was used as 
criterion of statistical significance. All statistical tests were performed by using IBM SPSS Statistics for Windows, Version 24.0 (IBM Corp., Armonk, NY, USA).

\section{Results}

The current analysis included 124 children who started atropine $0.5 \%$ treatment for progressive myopia. Informed consent was obtained from all parents of children and all children aged 12 years or older.

Demographics of the study population are summarized in Table 1 . Gender was evenly distributed and the median age was 9.5 years (IQR: 4). The majority of children (66.9\%) had European ethnicity. Median SER 1 year prior to the study was $-3.88 \mathrm{D}$ (IQR: 4.00). At baseline, median SER was $-5.03 \mathrm{D}$ (IQR: 3.08) demonstrating an annual progression rate of SER of more than 1D prior to treatment. High myopia (SER $\leq-6 \mathrm{D})$ was present in $46(37.1 \%)$ of children (range: -6.13 to $-17.06 \mathrm{D}$ ); median AL was 25.14 (IQR: 1.30). Parental myopia was reported by $80.6 \%$; high parental myopia by $37.9 \%$.

Results of outcome and adherence are shown in Table 2. Of the 124 children, 89 (71.8\%) stayed on treatment during the full 3 years of follow-up, of these, 31 (34.8\%) stayed on $0.5 \%$ atropine, $32(36.0 \%)$ increased in dose to $1 \%$, and 26 $(29.2 \%)$ children decreased in dose. Decreasing the dose did not lead to rebound growth of AL. Of those who ceased therapy, $9(6.8 \%)$ children stopped due to an allergic reaction following the eye drops; 17 (13.6\%) children stopped due to photophobia and non-eye-related adverse events; and $9(6.8 \%)$ were lost to follow-up. The 17 children who ceased therapy due to adverse events did so primarily during the first 3 months of treatment. Risk factors for nonadherence were not significant although children who ceased therapy were somewhat older.

In those who fulfilled 3 years of treatment, the median annual progression of SER was $-0.25 \mathrm{D}$ (IQR: 0.44); of AL $0.11 \mathrm{~mm}$ (IQR: 0.18). Figure 1 represents the median annual progression rate of SER. Median progression was reduced to $0.00 \mathrm{D}$ in the 1 st year, and -0.41 and $-0.38 \mathrm{D}$ in the $2 \mathrm{nd}$ and 3 rd year (all $p<0.01$ ). Comparing these progressions to those prior to treatment, annual reduction rates of SER were 100, 65, and 68.2\% (all $p<0.01$; Fig. 1).

The correlation between SER and AL measured during the study was strong with Pearson's $R: 0.82(p<0.01)$. Annual progression of AL was $0.04 \mathrm{~mm}$ in the 1st year, and 0.16 and $0.14 \mathrm{~mm}$ in the 2nd and 3rd year, respectively (Fig. 2). We could not compare these progressions with those prior to treatment, as AL had not been measured by the referring clinics 1 year prior to treatment.

With respect to treatment response, $76 \%$ of children stayed stabilized within $-0.5 \mathrm{D}$ of SER progression during
Table 1 Distribution of demographics and clinical measures of children eligible for the study.

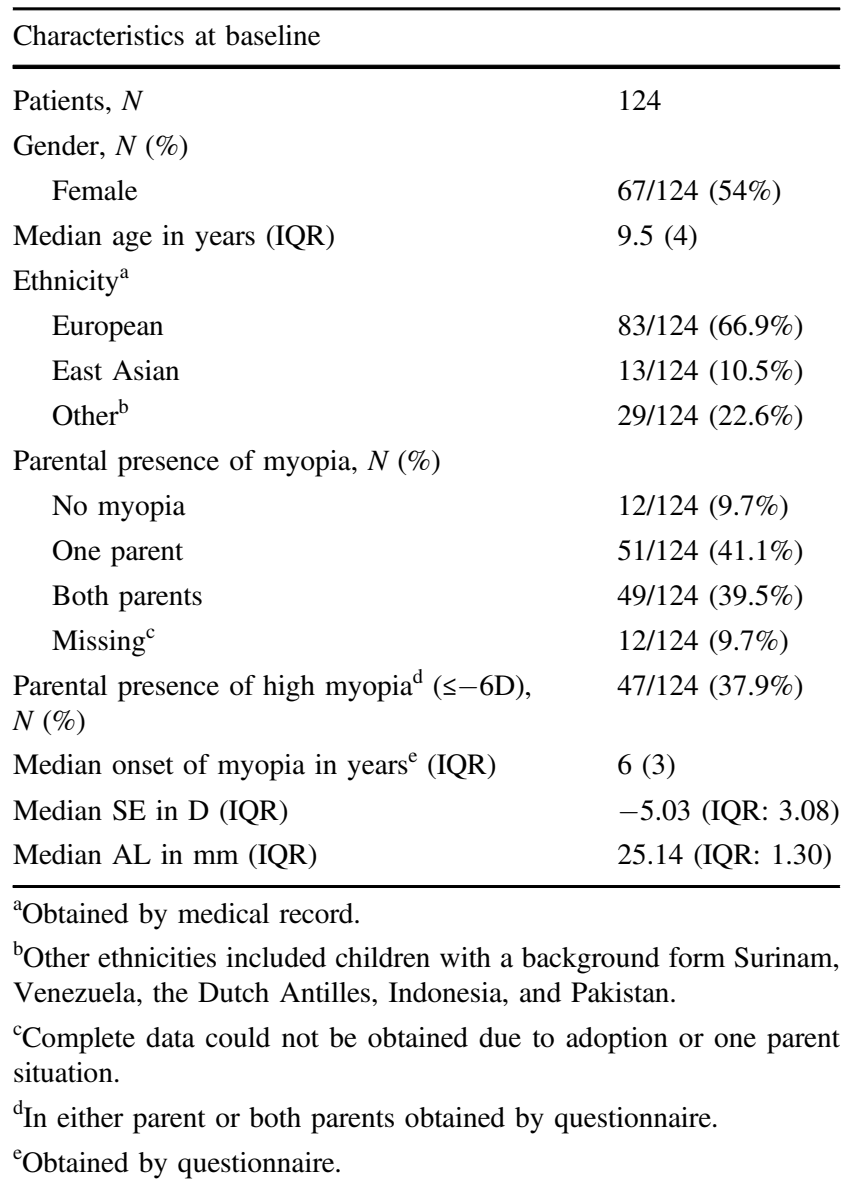

the 1st year; and 53 and $61 \%$ in the 2nd and 3rd year, respectively (Fig. 3a). AL progression in the 1st year stayed within $0.2 \mathrm{~mm}$ in $76 \%$; in the 2 nd year in $61 \%$, and in the 3rd year in $74 \%$ (Fig. 3b).

Age was moderately but significantly related to the treatment effect (Pearson's $R$ for SER: 0.31, $p<0.01$; for AL: $0.55, p<0.01)$. Children younger than 10 years of age at the start of therapy had lower treatment effect (median annual progression rate for SER: $-0.29 \mathrm{D}, \mathrm{IQR}$ : 0.44; for AL: 0.20, IQR: 0.18) than older children (median annual progression rate for SER: -0.19D, IQR: 0.41; for AL: 0.06, IQR: 0.08). None of the other determinants at baseline (SER; ethnicity; gender) were significantly associated with annual progression rate during treatment.

We increased the dose of atropine to $1 \%$ in $32 / 89$ (36.0\%) children (median progression: $-0.69 \mathrm{D} /$ year, IQR: 0.72; AL: $0.39 \mathrm{~mm} /$ year, IQR: 0.19) after a median time of 18 months. This did not diminish progression rates substantially: rates were SER: $-0.63 \mathrm{D} /$ year (IQR: 0.85 ) and AL: $0.34 \mathrm{~mm} /$ year (IQR: 0.30 ) during the remaining time of the study.

Aside from the photophobia and reading difficulties, other reported adverse events were nightmares by one child 
Table 2 Progression of spherical equivalent and axial length for children receiving atropine $0.5 \%$ as a starting dose.

\begin{tabular}{|c|c|c|c|c|c|c|}
\hline & \multicolumn{3}{|c|}{ Continued therapy $N=89(71.8 \%)$} & \multicolumn{3}{|c|}{ Ceased therapy $N=35(28.2 \%)$} \\
\hline & $\begin{array}{l}\text { Increased } \\
\text { dose } N=32\end{array}$ & $\begin{array}{l}\text { Decreased } \\
\text { dose } N=26\end{array}$ & $\begin{array}{l}\text { Same dose } \\
N=31\end{array}$ & $\begin{array}{l}\text { Allergy stop } \\
N=9\end{array}$ & $\begin{array}{l}\text { Adverse } \\
\text { events }^{\mathrm{c}} \\
N=17\end{array}$ & $\begin{array}{l}\text { Lost to } \\
\text { follow-up } \\
N=9\end{array}$ \\
\hline $\begin{array}{l}\text { Median age (year) } \\
\text { myopia onset (IQR) }\end{array}$ & $6.0(3)$ & $7.0(4)$ & $6.0(4)$ & $6.0(5)$ & $6.0(5)$ & $7.0(6)$ \\
\hline $\begin{array}{l}\text { Median age (year) at } \\
\text { baseline (IQR) }\end{array}$ & $8.5(3)$ & $11.0(4)$ & $9.0(3)$ & $9.0(4)$ & $11.0(5)$ & $12.0(6)$ \\
\hline \multicolumn{7}{|c|}{ Median spherical equivalent (SE) in D } \\
\hline $\begin{array}{l}1 \text { year prior to } \\
\text { treatment }\end{array}$ & $-4.5(4.9)$ & $-2.9(3.9)$ & $-3.8(3.1)$ & $-3.6(6.4)$ & $-4.3(4.5)$ & $-4.8(4.1)$ \\
\hline Baseline & $-5.8(3.5)$ & $-4.4(2.8)$ & $-4.9(2.8)$ & $-5.4(4.9)$ & $-5.3(4.0)$ & $-5.4(3.0)$ \\
\hline 1st year & $-6.0(3.6)$ & $-4.2(3.5)$ & $-4.8(2.5)$ & $-7.5(6.7)$ & $-5.6(3.7)$ & - \\
\hline 2nd year & $-6.9(4.7)$ & $-4.6(2.8)$ & $-5.2(2.6)$ & $-8.0(5.5)$ & $-6.8(3.3)$ & - \\
\hline 3rd year & $-7.5(5.2)$ & $-4.8(2.6)$ & $-5.6(2.6)$ & $-8.1(6.0)$ & $-7.8(3.7)$ & - \\
\hline \multicolumn{7}{|c|}{ Median progression rate of $\mathrm{SE}$ in D/year } \\
\hline $\begin{array}{l}1 \text { year before } \\
\text { treatment }\end{array}$ & $-1.0(1.3)$ & $-1.3(1.0)$ & $-1.0(1.2)$ & $-1.1(2.1)$ & $-0.8(1.1)$ & $-0.4(1.0)$ \\
\hline 1st year & $-0.4(0.6)$ & $+0.2(0.7)$ & $+0.1(0.5)$ & $-0.4(0.7)$ & $-0.7(1.1)$ & - \\
\hline 2nd year & $-0.6(0.7)$ & $-0.3(0.4)$ & $-0.3(0.6)$ & $-0.9(1.3)$ & $-0.8(0.9)$ & - \\
\hline 3rd year & $-0.5(0.8)$ & $-0.3(0.3)$ & $-0.3(0.5)$ & $-0.4(1.4)$ & $-0.9(1.1)$ & - \\
\hline \multicolumn{7}{|c|}{ Median axial length $(\mathrm{AL})$ in $\mathrm{mm}^{\mathrm{a}}$} \\
\hline Baseline & $25.2(1.3)$ & $24.7(1.3)$ & $25.4(1.6)$ & $25.2(2.8)$ & $24.8(1.2)$ & $25.9(2.5)$ \\
\hline 1st year & $25.5(1.7)$ & $24.5(1.5)$ & $25.3(1.6)$ & $25.4(1.5)$ & $25.1(1.3)$ & - \\
\hline 2nd year & $25.8(1.4)$ & $24.7(1.3)$ & $25.3(1.6)$ & - & - & - \\
\hline 3rd year & $25.9(2.3)$ & $24.8(1.5)$ & $25.4(1.5)$ & - & - & - \\
\hline \multicolumn{7}{|c|}{ Median progression rate $\mathrm{AL}$ in $\mathrm{mm} / \mathrm{year}^{\mathrm{a}}$} \\
\hline 1 st year & $0.3(0.2)$ & $0.0(0.2)$ & $0.0(0.1)$ & $0.2(0.3)$ & $0.3(1.0)$ & - \\
\hline 2nd year & $0.3(0.3)$ & $0.1(0.1)$ & $0.1(0.2)$ & - & - & - \\
\hline 3rd year & $0.2(0.3)$ & $0.1(0.1)$ & $0.1(0.1)$ & - & - & - \\
\hline
\end{tabular}

${ }^{\mathrm{a}} \mathrm{AL}$ was not included in the standard ophthalmological examination 1 year prior to start of therapy and was not included in the children who stopped atropine treatment.

${ }^{b}$ Allergies developed after 1 year. First-year data are on treatment, 2 nd and 3rd year were without treatment.

${ }^{\mathrm{c}}$ Adverse events included photophobia, reading difficulties, nightmares, and deterioration of behavioral problems in a child with diagnosis of ADHD. and deterioration of behavioral problems in a child with ADHD. No serious adverse events such as tachycardia, acute angle-closure glaucoma, pyloric obstruction, or asthma were reported.

\section{Discussion}

This study aimed to investigate the effectiveness of atropine for progressive myopia in a European clinical setting. We treated 124 children who presented with either a high degree of myopia or a high progression rate of SER with atropine eye drops at a starting dose of $0.5 \%$, and followed these children for 3 years. Of these, 89 (71.8\%) were persistent with therapy during the total duration of the study period. Median SER progression rates declined to 0.00D in the 1 st year and to -0.41 and $-0.38 \mathrm{D}$ in the 2 nd and $3 \mathrm{rd}$ year, respectively. This corresponded well with a median progression rate for $\mathrm{AL}$ of $0.04 \mathrm{~mm}$ in the $1 \mathrm{st}$ year, and 0.16 and $0.14 \mathrm{~mm}$ in the 2nd and 3rd year, respectively. Despite the slightly lower effect in the 2nd and 3rd year, $61 \%$ of children still had $<-0.5 \mathrm{D}$ of SER progression, and $74 \%$ had $<0.2 \mathrm{~mm}$ AL elongation during the last year of the study. After the 1st year, 32/89 of patients progressed $0.3 \mathrm{~mm}$ or more while on the starting dose, and were switched to atropine $1 \%$. By contrast, $26 / 89$ stabilized to $0.1 \mathrm{~mm} /$ year or less, and were allocated to lower dosages. An important determinant of treatment effect was age: those older than 10 years at baseline remained more stable than those younger.

Given the design of this clinical trial, this study has strengths and limitations. We chose to study high-dose atropine in a real world setting because randomized controlled trials had already demonstrated ample evidence of safety and efficacy of this treatment [10, 15, 20-24]. Our primary intention was to investigate its implementation in Europeans, and our clinical setting enabled great generalizability of findings. Other merits of the study were the long follow-up period and detailed investigation including cycloplegic refraction and AL. A limitation of our design was the use of pretreatment SER progression rates as a reference rather than a separate control group [25]. It is known that myopia progression rates slow down with age, 


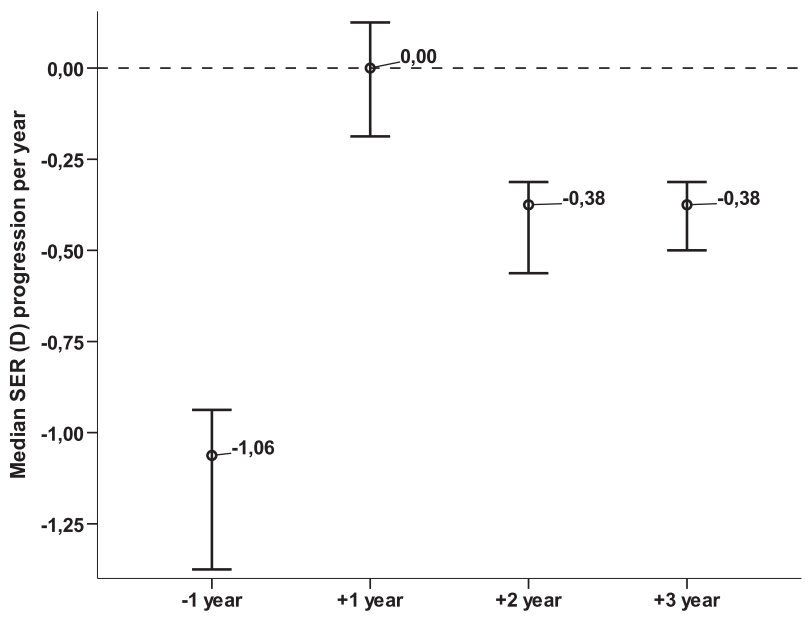

Fig. 1 Median Spherical Equivalent (SER) change in dioptres per year in children treated with atropine $0.5 \%$ for progressive myopia. Error bars represent the $95 \%$ Confidence Interval.

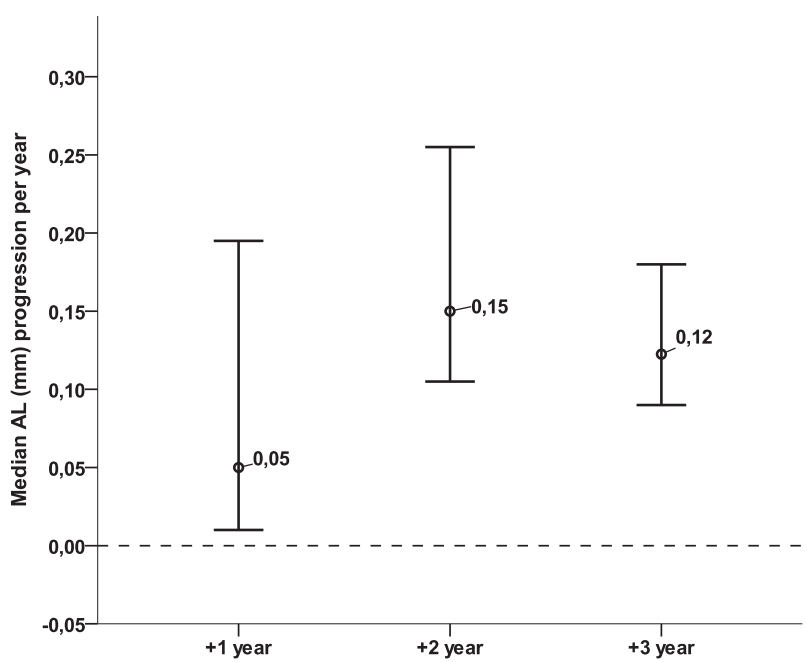

Fig. 2 Median Axial Length (AL) change per year in millimeters in children treated with atropine $0.5 \%$ for progressive myopia. Error bars represent the $95 \%$ Confidence Interval.

and this effect may have influenced our findings [26]. In all children who prolonged therapy an initial arrest of the myopia progression was seen in the 1 st year but median progression continued in the 2nd and 3rd year with -0.41 and $-0.38 \mathrm{D}$. However, most progression in those who dropped out of therapy continued at higher rates $(-0.9 \mathrm{D})$, implying that treatment effects were real. It is plausible that those whose myopia progressed at a higher rate would be more likely to be referred to our clinic and participate in this study.

Although atropine $0.01 \%$ is becoming widely accepted due to minimal side effects and is the preferred treatment in several established practice guidelines, the reported efficacy is lower than that of high-dose atropine [27-29]. The ATOM study showed twice as much control with atropine
0.5 vs. $0.01 \%$ (annual progression of SER: $-0.24 \mathrm{D}$ vs. $-0.46 \mathrm{D}$; of AL: 0.19 vs. $0.33 \mathrm{~mm}$ ) and the LAMP study found a similar dose effect when comparing 0.05 to $0.01 \%$ (annual progression of SER: $-0.27 \mathrm{D}$ vs. $-0.59 \mathrm{D}$; of AL: 0.20 vs. $0.41 \mathrm{~mm}$ ) $[15,30]$ In our study on children with already high refractive errors (median SER: $-5.03 \mathrm{D}$ ), we aimed to achieve the best possible myopia control. Our data complement the earlier randomized controlled trials in Asians, as atropine $0.5 \%$ in our study demonstrated similar responses as ATOMII (Median annual SER: $-0.25 \mathrm{D}$; AL: $0.11 \mathrm{~mm})[10,15]$.

Seventeen children ceased therapy, most in the first months after the start, because of disturbances of accommodation or photosensitivity; 9 children stopped atropine because of an allergy, mostly due to an allergic conjunctivitis; and 2 stopped because of mild non-eye-related reasons. Nine children were lost to follow-up and did not return after their initial start of therapy. Serious systemic adverse events affecting heart, lung, or intestines described for other routes of atropine administration did not occur. Comparing our data to the $0.5 \%$ users of the ATOM study, we noticed many similarities [15]. The proportion of reported allergic conjunctivitis was slightly higher (7/124; $5.6 \%)$ probably related to the preservative benzalkonium chloride. Our study on mostly European children had more dropouts $(N=26 ; 21 \%)$ than studies on the more pigmented Asians (13.7\%). Similar to ATOM, we found that photosensitivity complaints were predominantly reported in the first months of treatment; these diminished after 3 months $[15,19]$. Adverse events more often led to nonadherence in teenagers than in younger children. Taken together, these observations suggest that remedies addressing the adverse events of high-dose atropine are warranted. We suggest the prescription of photochromic progressive spectacles and a cap for outdoor activity.

This clinical trial shows that findings from the ATOMII trial can be applied to clinical practice, also in Europe. The high-dose atropine group in ATOM I and II experienced strong reduction of the annual myopia progression rate with close to stabilization of SER $(+0.03 \pm 0.5 \mathrm{D})$ in the 1 st year; and mild progression of $-0.28 \pm 0.92 \mathrm{D}$ in the 2 nd year [10]. In our study, complete stabilization of SER (0.00D) was achieved during the 1st year. Progression of SER during the 2nd year was $-0.41 \mathrm{D}$, albeit somewhat higher than the reduction under trial circumstances. Two other observational studies reported long-term results after high-dose atropine, both were executed in mild myopes $>25$ years ago and showed close to stability of refractive error [31, 32]. Our study reports long-term follow-up of more severe myopes on high-dose atropine, and our data shows that progression during the 3 rd year $(-0.38 \mathrm{D})$ did not increase further, showing stabilization of atropine efficacy. Despite the fact that myopia progression diminishes with age and 

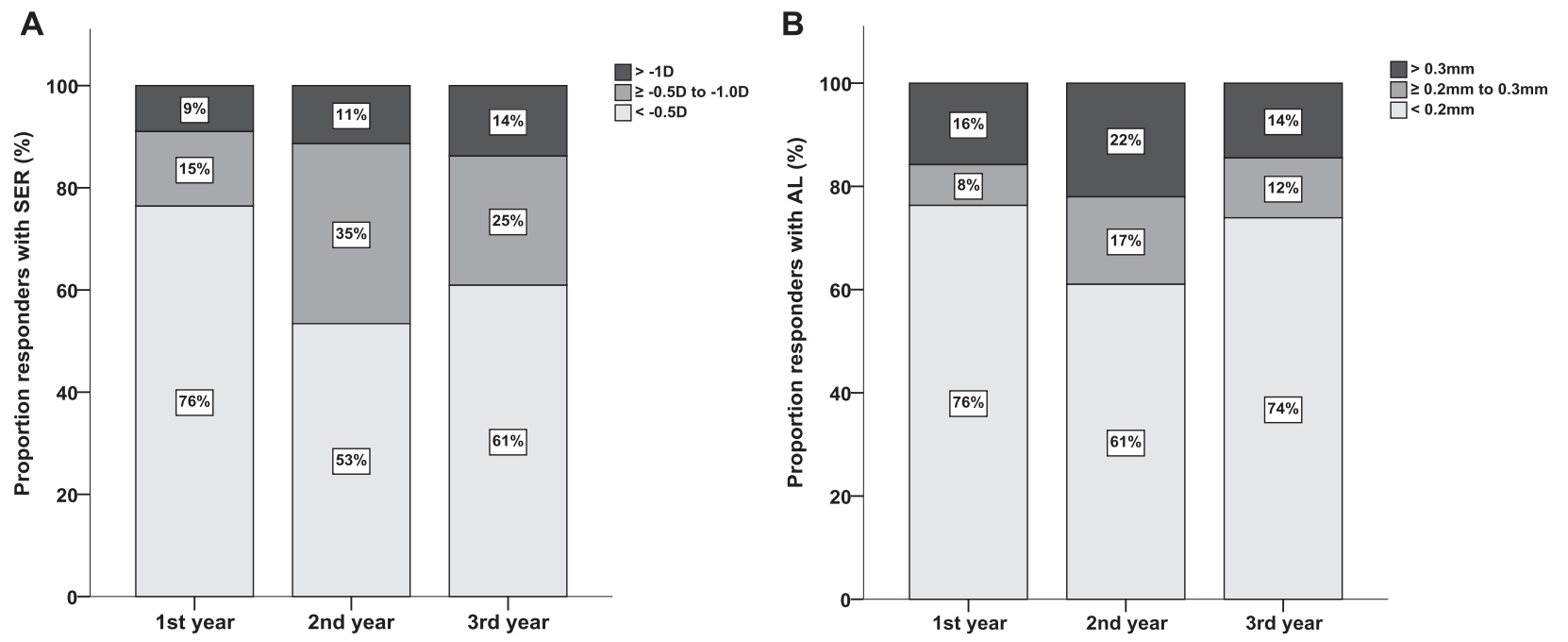

Fig. 3 Proportion of good (light gray), moderate (dark gray), and poor (black) responders with respect to spherical equivalent of refraction (a) and axial length (b) in children on therapy for 3 years.

some of the effect seen during our 3-year follow-up reflects the natural reduction of progression, no significant difference $(p=0.08)$ in progression could be detected between children 10 years or younger, or older children. An intriguing question is whether atropine therapy has a lower effect on myopia progression in Europeans than in Asians. Comparison of annual progression rates shows that atropine $0.5 \%$ leads to $-0.22 \mathrm{D} / \mathrm{year}$ in Asian randomized trials and to $-0.24 \mathrm{D} /$ year in other Asian studies, while atropine $0.5 \%$ in our European study leads to a median annual progression of $-0.24 \mathrm{D} /$ year over a 2 -year study period $[10,21,33]$. These figures suggest that ethnic differences in efficacy are minimal.

The biological effect of atropine, a nonselective muscarinic receptor antagonist, remains unclear. The retina and sclera have been suggested as target sites since both tissues harbor muscarinic acetylcholine receptors (mAChR) [34]. A study in guinea pigs found that atropine treatment decreased a regulator of G-protein signaling (a group of mAChRs) mRNA expression and increased collagen type I mRNA expression in sclera. More conclusive evidence whether blockage of $\mathrm{mAChR}$ directly interferes with axial elongation is lacking [35]. Several animal studies suggest that atropine therapy prevents eye growth through nitric oxide (NO) production; inhibition of NO interferes with atropine's effect [36]. Other indirect effects may be through dopamine, as studies have shown that intravitreal injections of atropine cause dopamine release in the retina [37]. Both NO and dopamine are known to act as stop signals for myopia progression [38].

We propose that atropine treatment should be customized according to age, risk of high myopia, and coping capacity with adverse events. One-third of the patients stayed on the starting dose $0.5 \%$ atropine, $29 \%$ responded so well after 1 year that the dose could be tapered. Lowering the dose did not lead to increased growth, and whether stopping causes a rebound phenomenon remains to be seen as this study continues. One-third responded rather poorly and was switched to the highest dose of atropine. Children who continued on atropine $0.5 \%$ or lower dosages showed a median annual progression rate of, respectively, $-0.19 \mathrm{D}$ (IQR: 0.3 ) and $-0.08 \mathrm{D}$ (IQR: 0.3). A stronger efficacy for atropine $1 \%$ has been well established by animal research as well as many clinical studies $[15,25,39]$. Children who needed the $1 \%$ treatment had an average median annual progression of $-0.52 \mathrm{D}$ (IQR: 0.4$)$ while on atropine $0.5 \%$, they had a younger median age $(p<0.01)$ and were more myopic at baseline, albeit not significantly $(-5.81 \mathrm{D}$ (IQR: 3.69 ) vs. $-4.63 \mathrm{D}$ (IQR: 3.47), $p=0.22$ ). The ATOM study disclosed the same risk factors for poor responders [40]. Unfortunately, switching to atropine $1 \%$ in those responding poorly, only slightly diminished growth further in our study. To prevent rebound growth, teenagers who reached stability of AL were tapered in atropine dose before stopping. This strategy prevented rebound of SER and AL, which did occur when high-dose atropine was abruptly stopped in those with allergic reactions. These nine children had an initial good SER response of $-0.4 \mathrm{D} /$ year (IQR: 0.7) in the 1 st year increased to $-0.9 \mathrm{D} /$ year (IQR: 1.3 ) in the 2nd year (Table 2).

In summary, this real world study provided SER and AL outcomes for $0.5 \%$ starting dose atropine in European children with progressive myopia. We addressed side effects, prescribed photochromic progressive spectacles at the start of the study, and diminished the risk of rebound growth by tapering the dose in children who had a stable SER and AL. With this regimen, 89/124 (71.8\%) children stayed on therapy for 3 consecutive years. Median annual 
progression of SER for children on therapy was $-0.25 \mathrm{D}$ (AL: $0.11 \mathrm{~mm}$ ), reflecting a nearly $75 \%$ reduction of myopia progression when compared with the rate before treatment. Our data imply that high-dose atropine should be considered a treatment option for severely progressing myopia, even in children with fair skin and blue eyes.

\section{Summary}

\section{What was known before}

- Several controlled trials have indicated that high-dose atropine $(0.5-1 \%)$ for treatment of progressive myopia is the most effective myopia control measure.

- Although effective, not many specialists in myopia control prescribe high-dose atropine.

\section{What this study adds}

- In a real world setting, $72 \%$ of children stayed on therapy for 3 years, despite the side effects.

- Similar to the controlled trials, we found the same effect control over myopia progression, also on the long term.

Acknowledgements We would like to express great appreciation to Professor H.J. Simonsz, MD PhD, for his work on myopia control from 2005 onwards. His ideas in the early days of pharmaceutical myopia control have formed the basis for the current study. We also thank all participating patients and the medical staff of Department Ophthalmology at Erasmus MC for enabling us to establish the first myopia control center in the Netherlands.

\section{Compliance with ethical standards}

Conflict of interest CCWC's work has been funded by the H2020; ERC consolidator; NWO VICI \& VIDI; Erasmus MC/Erasmus University; and several charity funds related to ophthalmology. She has received compensation as a consultant for Novartis, Bayer, for Laboratory Thea, Nevakar. JRP has also received compensation as a consultant for Laboratory Thea. ET, SD, SEL, H-LW, AS, and JWLT declare no potential conflict of interest.

Publisher's note Springer Nature remains neutral with regard to jurisdictional claims in published maps and institutional affiliations.

Open Access This article is licensed under a Creative Commons Attribution 4.0 International License, which permits use, sharing, adaptation, distribution and reproduction in any medium or format, as long as you give appropriate credit to the original author(s) and the source, provide a link to the Creative Commons license, and indicate if changes were made. The images or other third party material in this article are included in the article's Creative Commons license, unless indicated otherwise in a credit line to the material. If material is not included in the article's Creative Commons license and your intended use is not permitted by statutory regulation or exceeds the permitted use, you will need to obtain permission directly from the copyright holder. To view a copy of this license, visit http://creativecommons. org/licenses/by/4.0/.

\section{References}

1. Jung SK, Lee JH, Kakizaki H, Jee D. Prevalence of myopia and its association with body stature and educational level in 19-year-old male conscripts in seoul, South Korea. Invest Ophthalmol Vis Sci. 2012;53:5579-83.

2. Williams KM, Verhoeven VJ, Cumberland P, Bertelsen G, Wolfram $\mathrm{C}$, Buitendijk GH, et al. Prevalence of refractive error in Europe: the European Eye Epidemiology (E(3)) Consortium. Eur J Epidemiol. 2015;30:305-15.

3. Flitcroft DI. Emmetropisation and the aetiology of refractive errors. Eye. 2014;28:169-79.

4. Wong YL, Saw SM. Epidemiology of pathologic myopia in Asia and worldwide. Asia Pac J Ophthalmol. 2016;5:394-402.

5. Morgan IG, Ohno-Matsui K, Saw SM. Myopia. Lancet. 2012;379:1739-48.

6. Wong TY, Ferreira A, Hughes R, Carter G, Mitchell P. Epidemiology and disease burden of pathologic myopia and myopic choroidal neovascularization: an evidence-based systematic review. Am J Ophthalmol. 2014;157:9-25.e12.

7. Tideman JW, Snabel MC, Tedja MS, van Rijn GA, Wong KT, Kuijpers RW, et al. Association of axial length with risk of uncorrectable visual impairment for Europeans with myopia. JAMA Ophthalmol. 2016;134:1355-63.

8. Wong YL, Sabanayagam C, Ding Y, Wong CW, Yeo AC, Cheung $\mathrm{YB}$, et al. Prevalence, risk factors, and impact of myopic macular degeneration on visual impairment and functioning among adults in Singapore. Invest Ophthalmol Vis Sci. 2018;59:4603-13.

9. Flitcroft DI. The complex interactions of retinal, optical and environmental factors in myopia aetiology. Prog Retin Eye Res. 2012;31:622-60.

10. Chua WH, Balakrishnan V, Chan YH, Tong L, Ling Y, Quah BL, et al. Atropine for the treatment of childhood myopia. Ophthalmology. 2006;113:2285-91.

11. Walline JJ, Jones LA, Sinnott L, Manny RE, Gaume A, Rah MJ, et al. A randomized trial of the effect of soft contact lenses on myopia progression in children. Invest Ophthalmol Vis Sci. 2008;49:4702-6.

12. Cho P, Cheung SW. Retardation of myopia in orthokeratology (ROMIO) study: a 2-year randomized clinical trial. Invest Ophthalmol Vis Sci. 2012;53:7077-85.

13. Li SM, Kang MT, Wu SS, Meng B, Sun YY, Wei SF, et al. Studies using concentric ring bifocal and peripheral add multifocal contact lenses to slow myopia progression in school-aged children: a meta-analysis. Ophthalmic Physiol Opt. 2017;37:51-9.

14. Walline JJ. Myopia control: a review. Eye Contact Lens. 2016;42:3-8.

15. Chia A, Chua WH, Cheung YB, Wong WL, Lingham A, Fong A, et al. Atropine for the treatment of childhood myopia: safety and efficacy of $0.5 \%, 0.1 \%$, and $0.01 \%$ doses (atropine for the treatment of myopia 2). Ophthalmology. 2012;119:347-54.

16. Chia A, Chua WH, Wen L, Fong A, Goon YY, Tan D. Atropine for the treatment of childhood myopia: changes after stopping atropine $0.01 \%, 0.1 \%$ and $0.5 \%$. Am J Ophthalmol. 2014;157:451-7.e1.

17. Pineles SL, Kraker RT, VanderVeen DK, Hutchinson AK, Galvin JA, Wilson LB, et al. Atropine for the prevention of myopia progression in children: a report by the American Academy of Ophthalmology. Ophthalmology. 2017;124:1857-66. 
18. Bullimore MA, Berntsen DA. Low-dose atropine for myopia control: considering all the data. JAMA Ophthalmol. 2018;136:303.

19. Polling JR, Kok RG, Tideman JW, Meskat B, Klaver CC. Effectiveness study of atropine for progressive myopia in Europeans. Eye. 2016;30:998-1004.

20. Shih YF, Chen CH, Chou AC, Ho TC, Lin LL, Hung PT. Effects of different concentrations of atropine on controlling myopia in myopic children. J Ocul Pharm Ther. 1999;15:85-90.

21. Shih YF, Hsiao CK, Chen CJ, Chang CW, Hung PT, Lin LL. An intervention trial on efficacy of atropine and multi-focal glasses in controlling myopic progression. Acta Ophthalmol Scand. 2001;79:233-6.

22. Yen MY, Liu JH, Kao SC, Shiao CH. Comparison of the effect of atropine and cyclopentolate on myopia. Ann Ophthalmol. 1989;21:180-2.

23. Yi S, Huang Y, Yu SZ, Chen XJ, Yi H, Zeng XL. Therapeutic effect of atropine $1 \%$ in children with low myopia. J Aapos. 2015;19:426-9.

24. Kumaran A, Htoon HM, Tan D, Chia A. Analysis of changes in refraction and biometry of atropine- and placebo-treated eyes. Invest Ophthalmol Vis Sci. 2015;56:5650-5.

25. Huang J, Wen D, Wang Q, McAlinden C, Flitcroft I, Chen H, et al. Efficacy comparison of 16 interventions for myopia control in children: a network meta-analysis. Ophthalmology. 2016;123:697-708.

26. Group C. Myopia stabilization and associated factors among participants in the Correction of Myopia Evaluation Trial (COMET). Invest Ophthalmol Vis Sci. 2013;54:7871-84.

27. Morgan IG, He M. An important step forward in myopia prevention: low-dose atropine. Ophthalmology. 2016;123:232-3.

28. Gong Q, Janowski M, Luo M, Wei H, Chen B, Yang G, et al. Efficacy and adverse effects of atropine in childhood myopia: a meta-analysis. JAMA Ophthalmol. 2017;135:624-30.

29. Leo SW. Scientific Bureau of World Society of Paediatric Ophthalmology and Strabismus Current approaches to myopia control. Curr Opin Ophthalmol. 2017;28:267-75.
30. Yam JC, Jiang Y, Tang SM, Law AKP, Chan JJ, Wong E, et al. Low-Concentration Atropine for Myopia Progression (LAMP) study: a randomized, double-blinded, placebo-controlled trial of $0.05 \%, 0.025 \%$, and $0.01 \%$ atropine eye drops in myopia control. Ophthalmology. 2019;126:113-24.

31. Kennedy RH, Dyer JA, Kennedy MA, Parulkar S, Kurland LT, Herman DC, et al. Reducing the progression of myopia with atropine: a long term cohort study of Olmsted County students. Binocul Vis Strabismus Q. 2000;15 3 Suppl 3:281-304.

32. Brodstein RS, Brodstein DE, Olson RJ, Hunt SC, Williams RR. The treatment of myopia with atropine and bifocals. A long-term prospective study. Ophthalmology. 1984;91:1373-9.

33. Chou AC, Shih YF, Ho TC, Lin LL. The effectiveness of $0.5 \%$ atropine in controlling high myopia in children. J Ocul Pharm Ther. 1997;13:61-7.

34. McBrien NA, Stell WK, Carr B. How does atropine exert its antimyopia effects? Ophthalmic Physiol Opt. 2013;33:373-8.

35. Zou L, Liu R, Zhang $X$, Chu R, Dai J, Zhou $H$, et al. Upregulation of regulator of G-protein signaling 2 in the sclera of a form deprivation myopic animal model. Mol Vis. 2014;20:977-87.

36. Carr BJ, Stell WK. Nitric oxide (NO) mediates the inhibition of form-deprivation myopia by atropine in chicks. Sci Rep. 2016;6:9.

37. Feldkaemper M, Schaeffel F. An updated view on the role of dopamine in myopia. Exp Eye Res. 2013;114:106-19.

38. Zhou X, Pardue MT, Iuvone PM, Qu J. Dopamine signaling and myopia development: what are the key challenges. Prog Retin Eye Res. 2017;61:60-71.

39. Diether S, Schaeffel F, Lambrou GN, Fritsch C, Trendelenburg AU. Effects of intravitreally and intraperitoneally injected atropine on two types of experimental myopia in chicken. Exp Eye Res. 2007;84:266-74.

40. Loh KL, Lu Q, Tan D, Chia A. Risk factors for progressive myopia in the atropine therapy for myopia study. Am J Ophthalmol. 2015;159:945-9. 